\title{
FREQUENCY OF RELAPSE OF STEROID SENSITIVE NEPHROTIC SYNDROME IN CHILDREN DURING THE FIRST YEAR AFTER COMPLETION OF SIX MONTHS STEROID THERAPY.
}

\footnotetext{
1. MBBS, FCPS

Senior Registrar Peadiatric Medicine The Children's Hospital \& ICH, Multan.

2. MBBS, FCPS (Peadiatrics Medicine) Associate Professor The Children's Hospital \& ICH Multan.

3. MBBS, FCPS

Assistant Professor Pedadtric Medicine

Children's Hospital \& ICH, Multan.
}

Correspondence Address:

Asim Khurshid

House No. 72, Nasheman Colony,

Bosan Road, Multan.

asimkhurshiddr@gmail.com

Article received on:

18/04/2019

Accepted for publication:

25/09/2019
Irum Jabeen', Asim Khurshid ${ }^{2}$, Tariq Aziz ${ }^{3}$

ABSTRACT... Objectives: Nephrotic syndrome (NS) is described as the existence of nephroticrange proteinuria along with edema, hyperlipidemia and hypoalbuminemia. NS is estimated to be 15 time more frequent in children as compared to adults. Relapse is a major problem while managing nephrotic children. This study was aimed to find out the frequency of relapse in children with first episode of steroid sensitive nephrotic syndrome (SSNS) during the first 12 months, after completion of 6 months steroid therapy. Study Design: Descriptive case series study. Setting: Department of Paediatric Nephrology, The Children's Hospital \& the Institute of Child Health, Multan. Period: From February 27, 2018 to February 27, 2019. Material and Methods: A total of 55 children, aged 1 to 10 years, diagnosed with SSNS, $1^{\text {st }}$ presentation of NS (based on history) and who successfully completed 6 months steroid therapy, were enrolled. They were taught to check proteinuria at home by dipstick method and enter daily results on the follow up card provided from the Nephrology department of the hospital. The outcome variable, that is relapse, was noted on the Proforma. Results: Amongst 55 children, gender distribution showed $38(69.1 \%)$ male and $17(30.9 \%)$ females. Children with body weight $<20 \mathrm{~kg}$ were 33 $(60 \%)$ and those having $\geq 20 \mathrm{~kg}$ were $22(40 \%)$. Patients with age $<6$ years were $54.5 \%$ and patients with age $\geq 6$ years were $45.5 \%$. Mean age was $5.93 \pm 3.36$ years. Frequency of relapse was noted to be $78.2 \%$ and patients who did not relapse within 1 year of completion of treatment were $21.8 \%$. Conclusion: Nephrotic syndrome is a common presentation of childhood renal problems and is major cause of morbidity in our set up. Relapses are frequently associated with SSNS and most of the patients relapse within 1 year of completion of treatment. Relapses are more common in male children as compared to female children.

Key words: $\quad$ Nephrotic Syndrome, Proteinuria, Relapse, Steroid Sensitive.

Article Citation: Jabeen I, Khurshid A, Aziz T. Frequency of relapse of steroid sensitive nephrotic syndrome in children during the first year after completion of six months steroid therapy. Professional Med J 2020; 27(3):558-562.

DOI: 10.29309/TPMJ/2020.27.3.3571

\section{INTRODUCTION:}

Nephrotic syndrome (NS) is considered to be the commonest chronic renal disease amongst children with the world-wide incidence of $2-3 / 100,000$ children per year ${ }^{1,2}$ but the incidence is higher in South Asia. ${ }^{3}$ NS is estimated to be 15 time more frequent in children as compared to adults. ${ }^{2-4}$ Researchers from New Zealand noted an incidence of 20 per million cases of NS amongst children aged less than 15 years. ${ }^{5}$ Occurrence of congenital NS has been documented as 1 in 10000 in Finnish origin. ${ }^{6}$

NS is described as heavy proteinuria ( $>40 \mathrm{mg} / \mathrm{m} 2$ ) $\mathrm{hr}$ ) along with hypoalbuminemia, hyperlipidemia and oedema. $^{7}$ Heavy proteinuria is the most important feature of nephrotic syndrome. ${ }^{8}$ This syndrome results from increased glomerular basement membrane permeability resulting in excessive filtration of plasma proteins with all its consequences. ${ }^{9}$ The NS was 1st described in $1827^{10}$, but, detailed account of idiopathic nephrotic children were initially detailed by Richet G. ${ }^{11}$

Primary or idiopathic nephrotic syndrome (INS) accountsformorethan $90 \%$ cases. It predominantly affects children aged 1-10 years, with more male affected than the female. ${ }^{12}$ The major histological types of nephrotic syndrome are minimal change disease (MCD), mesangioproliferative glomerulonephritis (MesPGN), focal segmental 
glomerulosclerosis (FSGS) and others. ${ }^{13}$

Corticosteroids are effective as first line treatment in most patients and early response to steroids is considered to be the best indicator for prognosis. ${ }^{14}$ Children who respond to steroids within 8 weeks of commencement of treatment are said to be having SSNS. Steriod resistance is labeled in children with no response to 8 weeks of steroid therapy.

Most of children suffering with SSNS follow a relapsing course while relapses are linked with higher risk of hypovolemia, thrombosis and infection. ${ }^{15}$ ISKDC (International Study of Kidney Disease In Children) recommends prednisolon as $60 \mathrm{mg} / \mathrm{m} 2 /$ day for $1^{\text {st }}$ episode of NS for four weeks, then followed by $40 \mathrm{mg} / \mathrm{m} 2$ on alternate days spanning another 4 weeks. ${ }^{16}$ It was found in Tehran, Iran, that $83.2 \%$ children experienced multiple relapses after following the recommended regimen. ${ }^{14}$

In our setting, we follow similar steroid regimen as recommended by ISKDC followed by slow tapering (25\% reduction of alternate day dose 4 weekly). This protocol takes almost 6 months period to complete the treatment course. As different steroid regimens are under trial seeking effective ways to minimize the risk of relapse of NS, the aim of our study was to determine the frequency of relapse during the first 12 months after completion of 6 months steroid therapy in children with first episode of SSNS. The results of our study will help to develop strategies to overcome relapse, which will be beneficial in further management of children with nephrotic syndrome.

\section{MATERIAL AND METHODS}

This was a descriptive case series study, conducted at the department of Paediatric Nephrology, The Children's Hospital \& the Institute of Child Health, Multan, from February 27, 2018 to February 27 2019. Approval from institute's ethical committee was taken for this study.

By taking confidence level, $1-a=95 \%$ as $1.96, P=$ $0.83,{ }^{6}$ absolute precision required as $d=0.10$, a sample size of 55 children was calculated. A total of 55 children, aged 1 to 10 years, diagnosed with SSNS, $1^{\text {st }}$ presentation of NS (based on history) and who successfully completed 6 months steroid therapy, were enrolled. Children having atypical NS (persistent hematuria, hypertension, deranged renal functions and hypocomplementemia), NS because of any systemic disease (like SLE, Hepatitis B \& C +ve) or steroid dependent NS were excluded.

NS waslabeledasthe presence ofall ofthefollowing features: proteinuria (spot urine protein creatinine ratio of more than 2), hypoalbuminemia (serum albumin less than $2.5 \mathrm{mg} / \mathrm{dl}$ ), hyperlipidemia (serum cholesterol more than $220 \mathrm{mg} / \mathrm{dl}$ ) and edema. SSNS was labeled in case of remission within 4 weeks of induction with oral prednisolone $60 \mathrm{mg} / \mathrm{m} 2 /$ day in 3 divided doses. Remission was defined as spot urine protein creatinine ratio less than 0.2 or proteinuria nil or trace on dipstick for 3 consecutive $1^{\text {st }}$ morning urine samples. Relapse was named as reoccurrence of proteinuria on dipstick $2+$ for 3 consecutive days or $\geq 3+$ for 1 day in early morning urine sample, in cases who were noted to have remission previously.

Consent was sought from parents / guardians of all the participants for this study. Demographic data along with detailed history of presenting complaints including age at onset, symptom's duration, facial or generalized edema, hematuria and oliguria were recorded. General physical examination including height and weight, $\mathrm{BP}$, and all systemic examination was done. Investigations included: spot urinary dipstick or urinary protein creatinine ratio for protein urea, complete urine examination, Complete blood count along with renal function tests, serum albumin and serum cholesterol were done.

Parents of those children who successfully completed 6 months steroid therapy were guided to check proteinuria at home using dipstick method and were given follow up cards from nephrology department of the hospital to note results on daily basis. Patients were kept on 4 weekly follow up. Relapse in the first 12 months in all selected patients was noted. A predesigned 
proforma was used to record all the study data. SPSS version 21.0 was used for data analysis. Mean and standard deviations were calculated from quantitative variables like age and weight. Frequency and percentage was calculated for qualitative variables like gender and relapse (Yes, No) which is the outcome variable. Effect modifiers were controlled by stratification. Chi square test was applied and $p$ value as less than 0.05 were considered as significant.

\section{RESULTS}

In this study, 55 patients with NS were observed. Studied population was divided into two age groups. Patients with age <6 years were $54.5 \%$ and patients with age $\geq 6$ years were $45.5 \%$. Mean age was $5.93 \pm 3.36$ years.

Gender of the patients is mentioned with $69.1 \%$ patients being male and $30.9 \%$ patients being female. Children included in the study were stratified according to body weight also. Children with body weight $<20 \mathrm{~kg}$ were $60 \%$ and those having $\geq 20 \mathrm{~kg}$ were $40 \%$. Mean weight amongst the children was 19.68 with standard deviation of $9.39 \mathrm{~kg}$ ranging from 6 to $51 \mathrm{~kg}$. Frequency of relapse was noted to be $78.2 \%$ and patients who did not relapse within 1 year of completion of treatment were $21.8 \%$. When children having relapse were compared with those who did not have any, age, gender and weight turned out to statistically insignificant in between the children ( $p$ value $>0.05$ )

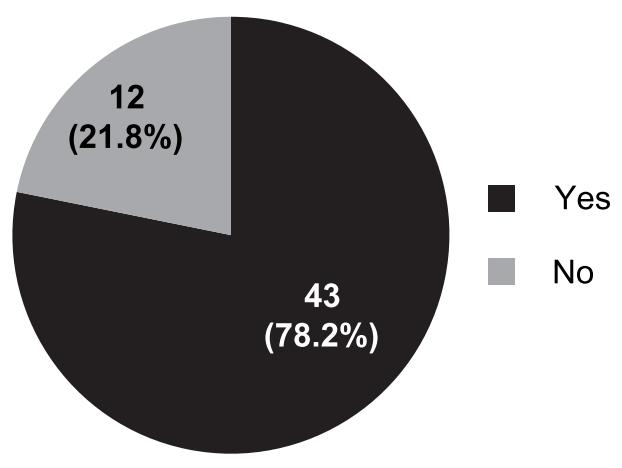

Figure-1. Frequency of relapse in children during the first 12 months after steroid therapy in first episode of SSNS $(n=55)$

\begin{tabular}{|c|c|c|c|}
\hline & \multicolumn{2}{|c|}{ Children Relapsed } & \multirow{2}{*}{ P-Value } \\
\hline & Yes $(n=43)$ & No $(n=12)$ & \\
\hline \multicolumn{4}{|c|}{ Age (years) } \\
\hline$<6$ & 24 & 6 & \multirow{2}{*}{0.721} \\
\hline$>6$ & 19 & 6 & \\
\hline \multicolumn{4}{|l|}{ Gender } \\
\hline Male & 30 & 8 & \multirow{2}{*}{0.837} \\
\hline Female & 13 & 4 & \\
\hline \multicolumn{4}{|l|}{ Weight } \\
\hline$<20$ & 26 & 7 & \multirow{2}{*}{0.894} \\
\hline$>20$ & 17 & 5 & \\
\hline
\end{tabular}

\section{DISCUSSION}

NS is a common renal problems of childhood worldwide. In most of the patients it is of steroid sensitive type. However relapses occur in $>60 \%$ of patients and associated with increased risk of infections and compliance of the patients is greatly affected. Different factors are responsible for relapses in Nephrotic syndrome, with inadequate steroid regimen leading the list above all.

This study was designed to determine the frequency of relapse within 1 year of completion of steroid treatment in children presenting with first episode of NS. In our study, relapse rate was lower as compared to study done by Esfahani Sayed Tahir et $\mathrm{al}^{15}$, who evaluated the clinical course and outcome of children with steroid sensitive nephrotic syndrome. Out of the total 226 children, mean age was 3.46 years, which in our study was found to be 5.93 years. There were $157(69.5 \%)$ male children and $69(30.5 \%)$ female children, which are also almost similar to our study. There were $83.2 \%$ patients who experienced relapse after being treated by ISKDC recommended regimen.

Anochie Ifeoma et $\mathrm{al}^{4}$ evaluated response to steroids in children between 1-16 years of age. There were equal male and female patients with a ratio of 1:1. Steroid regimen consisted of standard ISKDC recommended followed by a tapering of $10 \mathrm{mg} /$ week. However in this study relapse rate was found to be $99 \%$, which is lot higher than our study. 
Elisabeth $\mathrm{M}$ Hodson et $\mathrm{al}^{16}$, in a meta analysis compared different durations along with total doses / regimens using any corticosteroid agent. Prednisolone given for 4 weeks followed by alternate day therapy for 6 months, was found to have minimized the relapse rate from $60 \% 33 \%$. In our study the whole treatment took about 6 months and alternated day was therapy was tapered slowly. However in our study the relapse rate was still high (78.2\%) despite 6 months steroid therapy.

Another study done by Mohammad Sjaifullah Noer et $\mathrm{al}^{17}$ while studying predictors of relapse in Steroid sensitive nephrotic syndrome revealed that out of 99 children 63(63.6\%) experienced relapse within 1 year of completion of steroid treatment given according to ISKDC recommended therapy. Out of total 99 children $77.8 \%$ were male and $22.2 \%$ female. $59.6 \%$ were having age $\leq 6$ years and $40.4 \%$ were $>6$ years. This study also showed that time interval between the $1^{\text {st }}$ steroid response and first relapse are significant predictors of relapse in future.

In another study done by Avrind Bagga et $\mathrm{al}^{18}$, effect of prolonged (16 weeks) versus standard (8 weeks) steroid therapy was compared for initial episode of SSNS. It was observed that out of total $72.7 \%$ experienced relapse by 1 year, however children receiving initial prolonged treatment (16 weeks) relapsed later in time. It was concluded that prolongation of the first steroid therapy delays occurrence of first relapse. In our study steroid therapy was prolonged for about six months, however time to relapse after achieving remission was not part of our study. Only total no of children who relapsed within 12 months of completion of treatment were noted, which was $78.2 \%$.

Children with SSNS should be kept on close follow up for at least 1 year. Children with first episode of SSNS should be treated with prolonged steroid therapy followed by slow tapering. Parents of children with SSNS should be counseled in detail about the prognosis and importance of compliance, so that the administration of medication, adherence to dietary restrictions, monitoring and follow up is ensured. On the basis of results of this study, we also suggest that further research work should be done on this topic so that a steroid regime could be devised which may help prevent relapses with minimal adverse outcomes.

\section{CONCLUSION}

Nephrotic syndrome is a common presentation of childhood renal problems and is major cause of morbidity in our set up. Relapses are frequently associated with SSNS and most of the patients relapse within 1 year of completion of treatment. Steroid sensitive Nephrotic syndrome is more common in male children as compared to female children. Recommended ISKDC regimen followed by slow tapering also resulted in frequent relapse, so a better regimen for effective prevention of relapses needs to be devised.

Copyright@ 25 Sep, 2019.

\section{REFERENCES}

1. Davin JC, Rutjes NW. Nephrotic syndrome in children: From bench to treatment. International Journal of Nephrology 2011; [6 pages]. Available from: http:// www.ncbi.nlm.nih.gov/pubmed/21904676.

2. Vogt BA, Avner ED. Nephrotic syndrome. In: Kliegman RM, Behrman RE, Jenson HB, Stanton BF, editors. Nelson textbook of pediatrics. Philadelphia, PA: Saunders; 2011. P. 1801-07.

3. Bagga A, Srivastava RN. Nephroticsyndrome. In: Srivastava RN, Bagga A, editors. Pediatric Nephrology. New Delhi: Jaypee; 2005. P. 159-200.

4. Anochie I, Eke F, Okpere A. Childhood nephrotic syndrome: Change in pattern and response to steroids. Journal of the National Medical Association 2006; 98(12):1977-1981.

5. Wong W. Idiopathic nephrotic syndrome in New Zealand children, demographic, clinical features, initial management and outcome after twelvemonth follow-up: Results of a three-year national surveillance study. J Paediatr Child Health. May 2007; 43(5):337-41 .

6. Niaudet P. Genetic forms of nephrotic syndrome. Pediatr Nephrol. Dec 2004; 19(12):1313-8.

7. Gordillo R, Spitzer A. The nephrotic syndrome. Paediatrics in Review 2009; 30(3):94-105. 
8. Becker DJ. Minimal change disease. Nephrology Rounds. 2008;6:304-066.

9. Appel GB. Glomerular disorders and nephrotic syndromes. In: Goldman L, Ausiello D, editors. Cecil Medicine. Philadelphea, Pa: Saunders Elsevier; 2007. Chap. 122.

10. Bright R. Reports of medical cases selected with a view to illustrating the symptoms and cure of diseases by reference to morbid anatomy. London: Longmans Green; 1827.

11. Richet G. Clinical nephrology in the European French-speaking countries from 1945 to 1960: A physiopathological tradition. Nephrologie Therap. 2009; 5(3):210-3.

12. Chowdhury E, Huq MN, Jagirdar MA. Pattern of nephrotic syndrome in children admitted in Bangladesh Medical College Hospital. Bangladesh Medical College Journal 2010; 15(2):67-73.
13. Arif MK, Arif M, Amjad N. A histopathological outlook on nephrotic syndrome: A pediatric perspective. Indian J Nephrol. 2016; 26(3):188-91.

14. Khan PA, Kundi MZ. Basis of paediatrics. 7th ed. Multan: Nishtar Books; 2008: 581-9.

15. Esfahani ST, Madani A, Asgharian F, Ataei N, Roohi A, Moghtaderi M, Rahimzadeh MH. Clinical course and outcome of children with steroid nephritic Syndrome. Pediatr Nephrol. 2011 Jul; 26(7) 1089-93.

16. Hodson EM, Willis NS, Craig JC. Corticosteroid therapy for nephrotic syndrome in children. Cochrane Database Syst Rev. 2007; 4(CD001533).

17. Noer MS, Predictor of relapse in steriod- sensitive nephrotic syndrome. Southeast Asian Trop Med public Health 2005 Sept 5:1313-1320.

18. Bagga A, Hari $p$, Srivastava RN. Prolonged versus standard prednisolone therapy for initial episode of nephrotic syndrome. Pediatr Nephrol 1999 Nov 20; 824-827.

\begin{tabular}{|c|l|l|c|}
\hline \multicolumn{4}{|c|}{ AUTHORSHIP AND CONTRIBUTION DECLARATION } \\
\hline Sr. \# & \multicolumn{1}{|c|}{ Author(s) Full Name } & \multicolumn{1}{c|}{ Contribution to the paper } & Author(s) Signature \\
\hline 1 & Irum Jabeen & $\begin{array}{l}\text { Data collection, Drafting, } \\
\text { Discussion. }\end{array}$ \\
\hline 2 & Asim Khurshid & $\begin{array}{l}\text { Idea, Methodology, } \\
\text { Literature review, Data } \\
\text { analysis, Proof reading. } \\
\text { Methodology, Literature } \\
\text { Review, Discussion. }\end{array}$ \\
\hline 3 & Tariq Aziz & ma sin \\
\hline
\end{tabular}

